$\mathbb{T}$ periodica polytechnica

\author{
Transportation Engineering \\ 36/1-2 (2008) $69-72$ \\ doi: 10.3311/pp.tr.2008-1-2.13 \\ web: http://www.pp.bme.hu/tr \\ (c) Periodica Polytechnica 2008
}

RESEARCH ARTICLE

\section{Safety management of traffic growth in air transportation}

\author{
Dóra Meyer / Balázs Sághi / Géza Tarnai
}

Received 2007-03-03

\begin{abstract}
The grounds of examination are such air traffic challenges as the traffic increase. The focus here is on the safety of commercial transport flights. This paper demonstrates how a technology transfer with three-point approach can elicit information that the aircraft, aerodrome and air traffic control require to fly the aircraft safely and efficiently in case of traffic growth, and the "soft" background, i.e. the legal and organisational base of it. This paper is intended as a portal for information exchange between rail and air transportation. It also refers to human factors, as possibly instable elements of the system, and because of these, the adaptation of fuzzy logic regarding safety-related systems and processes.
\end{abstract}

\section{Keywords}

air traffic growth $\cdot$ technology transfer $\cdot$ safety

\section{Dóra Meyer}

Department of Control and Transport Automation, BME, Bertalan L. u. 2. H1111 Budapest, Hungary

e-mail: meyer.dora@mail.bme.hu

\section{Balázs Sághi}

Department of Control and Transport Automation, BME, Bertalan L. u. 2. H1111 Budapest, Hungary

e-mail: saghi.balazs@mail.bme.hu

\section{Géza Tarnai}

Department of Control and Transport Automation, BME, Bertalan L. u. 2. H1111 Budapest, Hungary

e-mail: tarnai.geza@mail.bme.hu

\section{Introduction}

The grounds of examination are such air traffic challenges as the traffic increase, which will be doubled in the next 20 years [1]. The increase is faster in Central Europe. The focus here is on the safety of commercial transport flights carrying passengers and/or freight receiving an Air Traffic Control (ATC) service, focusing mainly, but not exclusively, on mid-air collision risk, and the safety issues of ground movements. This paper is intended as a portal for information exchange between rail and air transportation, also refers to human factors, as possibly instable elements of the system, and because of these, the adaptation of fuzzy logic regarding safety-related systems and processes.

Concerning safety-related aspects, the two modes of transportation are intercorrected along the following three points of view: automation of ground operations in air transportation, human factors, and as a result, the paper contains a preliminary evaluation contributing to the reduction of gaps in these systems, furthermore enables the exploration of such new applications, like the use of fuzzy logic based modelling system.

\section{Standards, assignments, and recommended prac- tices}

Regarding air transportation the dominant view of current procedures is based on unified way of looking. The International Civil Aviation Organisation (ICAO), a specialised agency of the United Nations, sets the minimum Standards and Recommended Practices (SARP) for international civil aviation. Individual States remain responsible for regulating their aviation industries, but have to take into account the requirements of the Convention (EU) and the minimum standards established by ICAO. In Europe the Joint Aviation Authorities (JAA) are responsible for the production and publication of Joint Aviation Requirements (JARs) and the associated guidance and administrative documents. The European Aviation Safety Agency (EASA) is taking over the responsibility for regulating airworthiness and maintenance issues within the EU Member States. The JAA will retain its present function for operations and licensing as well as airworthiness and maintenance issues for the JAA member states outside EASA [2]. Note, that even if in the 
air transportation the safety management system has comprehensive way of looking, there can be also found gaps, by reason of which the safety management system has to be checked. The Group of Aerodrome Safety Regulators (GASR) has produced a set of requirements for the systematic management of safety, in an effort to harmonise the regulatory approach to the "how" of aerodrome operations to complement the "what" that is provided by ICAO SARPs. It is understood that a National Aviation Safety Authority according to national legislative provisions will adopt the requirements. The regulator is the Civil Aviation Authority (CAA) Safety Regulation Group (SRG). Different countries have different kinds of structures, but the responsibilities and professional tasks are broadly similar.

Regarding this issue an aerodrome organisation shall routinely carry out safety audits to provide assurance of the safety of activities and to confirm compliance with the safety requirements and the safety management system (SMS), by

- establishing a reporting system for accident and incidentreporting ensuring that the National Aviation Safety Authority is informed of the aviation safety aspects in connection with the operation of the Aerodrome;

- establishing and maintaining procedures for ability to trace all documents and data related to the SMS [3].

For aerodrome operators there are provisions written in ICAO Annex 14 about implementation of an SMS. ICAO has also issued a Manual on Aerodrome Certification that includes SMS, Doc. 9774. For the Flight Operations side JAA has issued JAR OPS 1 and 3 containing Quality System requirements. Aircraft Operators and Air Navigation Service Providers, may contribute towards risks that could affect the aircraft operations. JAR 25/1309 and ESARR 4 (Eurocontrol Safety Regulatory Requirement Number 4) can be used and adapted depending upon the area of operation that the risk analysis is focused on. Hazard identification and risk management are proactive methods in that there are the systematic examination of potentially hazardous activities to establish safe, effective procedures and practices. Analysis of hazardous activities will identify areas of relatively higher risk that require monitoring. This enables defences to be developed and contingency plans to be produced and implemented. Risk assessment matrices facilitate conclusions about what combination of probability of occurrence and seriousness of consequences may be accepted as tolerable levels of risk. Incidentally: regarding rail and air transportation these limit values and procedures are not very far from each other, although these are not interdependently developed, and for instance in pursuance of quantifying parts of the risk analysis in aviation tolerable hazard rates are derived by Functional Hazard Assessment (FHA) without an analysis of statistics [4]. An Aviation Community organisation with its facilities, equipment and systems shall be designed and operated so that for any risk the combination of probability of occurrence and seriousness of the consequences of the hazard frequency must not result in a level of risk that is unacceptable [5, 6].

\section{Critical points of air traffic growth}

Relation between the number of flights and the rate of accidents is quadratic. In case of three flights there are three potential conflicts (Fig. 1), but in case of six ones there are twelve potential conflicts (Fig. 10), in the air. [7, 8].

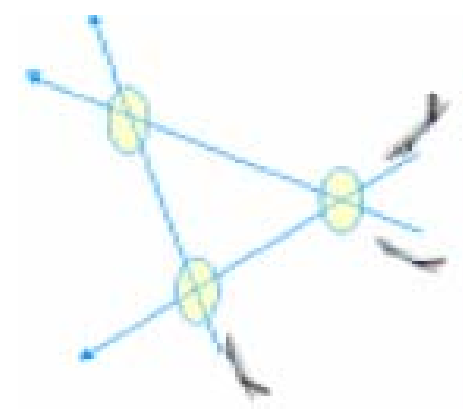

a.

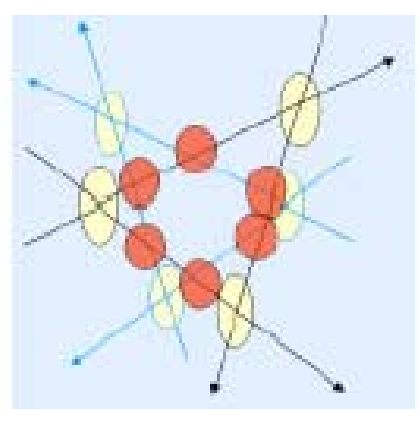

b.
Fig. 1. Conflict points in case of three and six flights

I.e. on the ground and also in the air the potential of airports must be revalued, new concepts wanted to guarantee the level of safety. The prime goal of the Air Traffic Management (ATM) system is to control accident risk.

On the ground two relevant points are in the safety-related, complex airport - air traffic control - aircraft system triangle regarding traffic growth, such as ramp safety and runway (RWY) incursions. Apron safety includes every single movements, actions on the airport, like for example ground operations related functions. This paper focuses on accent on runway incursions. The causes of these cases are mainly human factors, as seen at Table 1

Tab. 1. Number of RWY incursions

\begin{tabular}{lcccc}
\hline \multicolumn{5}{c}{ Number of RWY incursions } \\
\hline \multirow{4}{*}{ Year } & \multicolumn{4}{c}{ Kind of failure } \\
\cline { 2 - 5 } & $\begin{array}{c}\text { Pilot } \\
\text { failure }\end{array}$ & $\begin{array}{c}\text { Operative } \\
\text { failure }\end{array}$ & $\begin{array}{c}\text { Pedestrian/vehicle } \\
\text { failure }\end{array}$ \\
\hline 2001 & 233 & 91 & 83 & 407 \\
2002 & 191 & 75 & 73 & 339 \\
2003 & 174 & 89 & 60 & 323 \\
2004 & 173 & 97 & 56 & 326 \\
2005 & 169 & 105 & 53 & 327 \\
2006 & 190 & 39 & 51 & 280 \\
\hline
\end{tabular}

In case of mid-air movements ATC is carried out by what are often termed Air Navigation Service Providers (ANSP), ATC uses several kinds of technical entity: communications, navigation, surveillance and data processing. Data processing links the continuous (CNS) functions. Communication systems, both air-ground and between controllers and ATC centres, including both voice and electronic data transmission, are an integral part of ATC: effective ATC requires the controller to communicate 
with the pilot. Surveillance also is now an integral part of ATC: radars are there so that controllers can see position information on screens. Navigation is different. Controllers do not navigate aircraft, but ANSPs do provide some ground aids for aircraft, while others are independent on-board systems (e.g. altimetry for vertical navigation) [9]. The area is shared by sectors. In case of traffic growth, the task of air traffic controllers is also shared. It means, that regarding mid-air movements, more sectors are opened. The same applies to Area Control Center (ACC) and Approach Control (APP) fields. The limit is approx. twelwe aircrafts per sector. That is a normal pressure for a controller. The influence of the human factor is obvious, and the question also: where is the limit of the actually used method?

\section{Technology transfer options for improving air safety}

ATC has information about the likely paths of flights, and therefore can pass instructions to the pilot that will provide safe passage on taxiways, runways and in flight. Currently the control of ground operation movements is performed by optical and radio navigation facilities, but the loop of information is closed by human decision. At the end of the information chain is either the pilot or the air traffic controller. This generates the question, whether with this method the required level of safety can be maintained in case of the estimated traffic growth. The possible solution can be the application of a much more automated ground operation system like e.g. in the rail transportation currently used interlocking, signalling and train control system.

\subsection{Looking at air transportation from the field of railway}

As trains are guided by the rails and the points in the track, railways can only be operated safely and efficiently with adequate means for signalling, train control and train communication. Today, while the cockpit is becoming increasingly automated, controllers and pilots still communicate by radio. Single European Sky ATM Research (SESAR) is the technological part of the single European sky initiative, launched in 2004 to reform the organisation of air traffic control. It will introduce new communication, control and computing technologies between the ground and the aircraft which will optimise the work of air traffic controllers and pilots [3]. It would like also to find new procedures to risk mitigation in Air Traffic Management (ATM). Despite of these developments, the safety view, applied in the railway transportation, does not appear in the air transportaton.: sign and intervention by safety equipments by the ground operations. The focus is still on the ATC, hereby human resources and sign, but not on direct intervention. In a related work [6], we underline that the actually used references, structures and strategies are poorly supported in the current system, and consequently this can be a source for air traffic controllers and pilots confusion and misunderstanding of radio communication. Instead of inventing new ways of presenting safety-related information other modes of transportation's own information use strategies should be supported and used.

\subsection{Human factors}

Many literature deal with human errors, human factors in the transportation, also discussed narrowed down regarding certain elements of air transportation, like the behaviour of pilots and air controllers [10], [11], [12]. In this case it is much more relevant issue because of the character of the transportation process, as can be seen from the previous pharagraph. The point of interest of these studies, that the examined person is always checked in oneself, or in restricted environment, like for example cockpit, but not as member with exact failure factor in the complex airport - air traffic control - aircraft system triangle. The result of such examinations shows up e.g., that the use of references, structures and strategies to inform design can produce more efficient displays, where pilots perform twice as fast and with less error [10]. After all, to manage as safety relevant, comlex air traffic process, every single human intervention point and its influence have to be accounted numerically, and the appropriate feedback has to be performed.

Hereby the failure behaviour of the system could be ensured. One of the implementation possibilities could be the use of fuzzy logic, and further refinement of the risk analysis could be the flight-specific risk analysis based on fuzzy logic decision model, human decision interlocked in a dynamic reaction plan.

\subsection{Application of fuzzy logic}

Fuzzy logic have been already applied in air transportation. On the score of aircrew rostering problem or airspace daily operational sectorization was discussed e.g. by fuzzy logic [13, 14]. The question is: in what circumstances can future accident risk really be modelled with sufficient precision, and how should it be assured with traffic growth and operational and technical changes? This section first outlines some background on important features of target levels of safety (TLS). The TLS relates to total system design. A TLS covers all aviation-related causes. It is usually derived by taking historical accident rates, which show a progressive reduction over time, and extrapolating forward, get tighter and tighter over time [15]. Mid-air collisions are now rare. Because of this rarity, it is not possible to estimate the current accident rate in Europe with great statistical confidence from historical data on accidents. Estimates of the future accident rate (an actual level of safety-ALS), given traffic growth and new operational and technical features, therefore rely on risk modelling. Risk modelling has to rely on an understanding of the causes represented in accident types, which necessarily includes extrapolation of present system features, in particular human performance and failure rates [9]. To include the effects of human factors, the human decision also has to be modelled in order to reveal the subjectivism of human decision. This could be depicted diagrammatically to show how complex the evolution of information with the help of fuzzy logic, the person and the infrastrutural background as a fuzzy controller is. It shows how information, coming from many sources, is constantly changing, and being affected by events throughout the 
ground movements and flight. As follows the "gate to gate" concept [16, 17] with taking into account the human factors, could be numerical realised.

\section{Summary}

Given traffic growth and new operational and technical features are subsystems, which necessarily include extrapolation of present system features, in particular human performance and failure rates. Despite of the growing number of flights, the planners still manage to incorporate the customers' wishes.

This paper is intended to serve all parties involved in aviation safety, including acting as a planning and a tracking tool to monitor progress in the relevant areas of activity and practical application. The objectives and fundamentals of the paper are addressed by different focus areas. Reviewing the causal factors of aircraft accidents in order to identify specific safety issues which must be addressed to reduce accident numbers and rates, attention must be paid to the reasons for regional variations in accident rates, which could be minimized by the aid of safety procedures, used in other transportation systems. In the paper three options were proposed:

1 Safety awareness by facilitating the effective sharing and use of aviation and railway safety data and information could be the first stage of the process.

2 Gaps filling to all safety-related fields, respectively enhance the identification of deficiency, the air navigation field provided by all sources, including participation in a dialog to explore ways to reduce impediments, to the communication of safety-related information.

3 Develop provisions and guidance materials for normal operations monitoring systems, such as fuzzy logic aided flightspecific risk analysis.

\section{References}

1 available at www. eurocontrol.int/statfor

2 ICAO DOC 9859 AN/460 Safety Management Manual (SMM), 1st ed., 2006.

3 available at http://www. aeif.org/

4 European Action Plan for Runway Incurson, EUROCONTROL, 2003. Group of Aerodrome Safety Regulators, IATA,ACI, BAA, NATS, DFS.

5 available at http://www.caa.co.uk/

6 Meyer D, Sághi B, Tarnai G, Tracks and wings - dialogue for safety, braunschweiger symposium: "forms/format", 2007.

7 Debels P, Eurocontrol crds hungarian aeronautical research workshop, Budapest, 2006.

8 available at http://europa.eu.int/

9 Brooker P, Air Traffic Management accident risk.Part 1: The limits of realistic modelling, Safety Science 44 (2006), 419-450.

10 Solodilova I, Whiteley JP, Uncovering the information needs in complex aerospace systems 91 (2006), 1566-1575.

11 Paula A, Desmond TW, Hoyes B, Workload variation, intrinsic risk and utility in a simulated air traffic control task: evidence for compensatory effects, Safety Science 22 (1996), no. I-3, 87-101.

12 Kirwantitle B, The role of controller in the accelerating industry of air traffic management, Safety Science 37 (2001), 151-185.
13 Teodorović D, Lucić P, A Fuzzy Set Theory Approach to the Aircrew Rostering Problem, Fuzzy Sets and Systems 95 (1998), 261-271.

14 Babić O, Krstić T, Airspace daily operational sectorization by fuzzy logic, Fuzzy Sets and Systems 116 (2000), 49-64.

15 Milius B, Gayentitle JT, Functional Hazard Assessment der Luftfahrt im Vergleich zu Risikoanalysen der Eisenbahn, Signal+ Draht 96 (2004), no. 10, 23-31.

16 Ale BJM, Towards a causal model for air transport safety — an ongoing research project, Safety Science 44 (2006), 657-673.

17 Meyer D, Airport Certification in Civil Air Transportation, TUB, Faculty of Transport Engineering Budapest, 2006. 